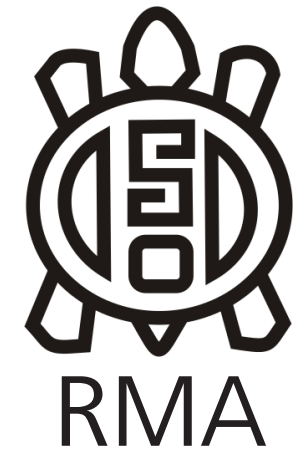

Museología

\title{
Entre la academización del conocimiento indígena y la indianización del Museo Integral de Laguna Blanca: discursos y prácticas en medio de procesos de indigenización
}

\author{
Between the academy of indigenous knowledge and the Indianization \\ of the Integral Museum of Laguna Blanca: speeches and practices in \\ the midst of indigenization processes
}

Daniel D. Delfino*, Sabine J. P. Dupuy** y M. Gustavo Pisani***

\begin{abstract}
*Museo Integral de la Reserva de Biosfera de Laguna Blanca, Instituto Interdisciplinario Puneño, Universidad Nacional de Catamarca, Argentina. E-mail: ddelfino@yahoo.com.ar **Museo Integral de la Reserva de Biosfera de Laguna Blanca, Instituto Interdisciplinario Puneño, Universidad Nacional de Catamarca, Argentina. E-mail: sabine.dupuy@yahoo.fr ${ }^{* * *}$ CONICET, Instituto Interdisciplinario Puneño, Universidad Nacional de Catamarca, Argentina. E-mail: mgustavopisani@yahoo.com.ar
\end{abstract}

\begin{abstract}
Resumen
La región de Laguna Blanca, al norte del departamento Belén (Puna catamarqueña, Argentina), es actualmente "amparada" por unas 120 unidades domésticas, repartidas a lo largo de los $10.000 \mathrm{~km}^{2}$ del Distrito. En el contexto regional actual, profundamente marcado por las sucesivas olas colonizadoras y neo-colonializadoras que siguen afectando a las poblaciones autóctonas latinoamericanas, reivindicamos la utilidad social de la producción de conocimiento científico y arqueológico y el necesario posicionamiento político y social de la práctica museológica. Buscamos por lo tanto, desde nuestra práctica, generar las condiciones y el espacio en una interacción con los campesinos e indígenas como sujetos históricos, para permitir un proceso de restauración de los saberes sometidos y subalternizados.
\end{abstract}

Palabras clave: museología social; ciencia socialmente útil; campesinado; comunidades indígenas; subalternidad.

\begin{abstract}
The region of Laguna Blanca, to the north of the department Belén (Puna catamarqueña, Argentina), is currently "protected" by some 120 domestic units, distributed along the $10,000 \mathrm{~km}^{2}$ of the District. In the current regional context, deeply marked by the successive colonizing and neo-colonial waves that continue to affect Latin American indigenous populations, we claim the social utility of the production of scientific and archaeological knowledge and the necessary political and social positioning of museological practice. We seek, therefore, from our practice, to generate the conditions and space in an interaction with the peasants and indigenous people as historical subjects, to allow a process of restoration of the subalternized and subjugated knowledge.
\end{abstract}

Keywords: Social museology; socially usefull science; peasantry; indigenous communities; subalternity.

\section{Laguna Blanca, ayer y hoy}

La región de Laguna Blanca, al norte del departamento Belén (Puna catamarqueña, Argentina), es actualmente "amparada" por unas 120 familias o unidades domésticas (Bender 1967), repartidas en cinco poblados principales y hábitats dispersos a lo largo de los 9.733

\footnotetext{
${ }^{1}$ Para las familias campesinas e indígenas de la Puna, la institución fundada en el Derecho Mayor que legitima la referencia a la tierra es el "amparo", en el sentido de cuidado de la tierra, un concepto muy alejado de la noción capitalista de tierra y posesión.
}

$\mathrm{km}^{2}$ del Distrito Laguna Blanca. Tradicionalmente, la economía regional se fundaba en el pastoreo de llamas, ovejas y cabras, la esquila de vicuñas y el hilado de la lana, la producción artesanal de textiles y la "horticultura de subsistencia" (Horkheimer 1990), complementadas por la recolección de productos y materiales locales (huevos, barro, leña, sal, etc.) y prácticas de intercambio. Sin embargo en los últimos cuarenta años se ha visto modificada drásticamente por una sucesión de factores exógenos. 
Así, un acelerado proceso de concentración poblacional se fue articulando con el establecimiento de instituciones gubernamentales y civiles en la localidad de Laguna Blanca tales como la Dirección de Ganadería, Escuela, Posta Sanitaria, Destacamento de Policía, Museo, Municipalidad, Dirección de Ambiente, Club Social y Deportivo, fuera de la institución de la Iglesia Católica. En este proceso se fueron instituyendo nuevas políticas y disposiciones, tanto económicas ${ }^{2}$, como jurídicas ${ }^{3}$ y socioculturales ${ }^{4}$, entre las cuales no es de menor importancia el hecho de que en la actualidad una mayoría de adultos han sido incorporados al empleo estatal o son beneficiarios de planes sociales estatales (empleo, seguridad social, entre otros). A esto se sumaron también nuevas prácticas de vida política partidaria como ser la elección de autoridades y la conformación de cuerpos políticos locales que encarnan en las localidades el complejo juego de contradicciones y tensiones de las políticas municipal, provincial y nacional.

El contexto regional actual está profundamente marcado por las sucesivas olas colonizadoras y neocolonializadoras que siguen afectando a las poblaciones autóctonas latinoamericanas. En consecuencia, 77 unidades domésticas del Distrito de Laguna Blanca se encuentran asentadas en el latifundio de la familia Pachado, que abarca 390.000 hectáreas, situación que podría describirse como el problema de la tierra: las familias campesinas tienen que arrendar la tierra en que han nacido, es decir pagar a los tenedores de supuestos títulos de propiedad por habitarla y por el derecho de pastaje o "yerbaje" por cada uno de sus animales (con valores diferenciales: de menor a mayor, ovejas y cabras, llamas y burros, vacas, mulas y caballos). Podemos retrotraer esta situación a la implementación de distintos mecanismos de apropiación de las tierras, ya en momentos de la colonia española, en los cuales personeros de la Colonia se hicieron con la propiedad privada de la tierra con los indios dentro, convirtiéndose en gamonales, en un sistema de feudalismo andino, y/o que posteriormente legitimaron en el aparato judicial de la República una institución colonial de vasallaje, como era la encomienda de indios. Al instrumentalizar la apropiación tanto de las tierras como de sus pobladores, estos mecanismos permitieron acaparar además la fuerza de trabajo indispensable para desarrollar las actividades de ganadería (Delfino, Espiro y Díaz 2007; Pisani 2017), dado que "La propiedad privada se produce sobre la base de desposesión; es decir, a partir de la negación,

\footnotetext{
2 Trabajo asalariado local y disponibilidad regular de dinero, circulación de mercancías que desplazan a las manufacturas locales, construcción de la ruta provincial $N^{\circ} 43$, etc.

3 Creación de la Reserva Natural de Vida Silvestre en 1979 y consecuentemente, aplicación efectiva de la ley de prohibición de la caza de vicuñas, creación de la Reserva de Biosfera en 1982, etc.

${ }^{4}$ Régimen escolar, reglamentaciones sobre conducta civil, régimen de salud pública, servicio militar obligatorio hasta comienzos de los '90 y posteriormente "por enganche", cultura deportiva, etc.
}

por la fuerza, de derechos preexistentes, con lo que la legitimidad de la propiedad se enraíza en un acto de fuerza devenido legítimo por el surgimiento de las nuevas disposiciones superestructurales" (Pisani 2017; Delfino y Pisani 2014).

En este contexto, también el pasado se constituye como objeto de conflicto, en tanto que las comunidades campesinas se reivindican en él como sujetos históricos y políticos, reconstituyendo su etnicidad y afirmando sus valores culturales y sus tradiciones. A las comunidades campesinas originarias de esta región no sólo se las ha enajenado de su territorio, sino que se ha sometido su cultura en un intento de imposición de otra, la de los vencedores (inkas, españoles, oligarquías y burguesías nacionales) y se ha abolido su condición histórica. Al campesino de Laguna Blanca se lo ha constituido como coya $a^{5}$ y en la "Civilización" el coya es el indio que se ha quedado atrás en la progresión histórica, un "atrasado" que aún habita la Puna, la "Barbarie": "Yo soy coya, pero no soy coya, no sé si me entiende", decía Rosalío V., tratando de que entendiéramos de que él era un habitante de la altura, y no renegaba de sus particularidades, pero no quería ser tratado como atrasado. Pero para la mirada blanca (que poco que ver tiene con el color de piel), el indio, el coya, no es, ontológicamente, sujeto como él: sólo está, es un objeto humano, vasallo o salvaje. Ahora bien, la objetividad del coya es establecida por la subjetividad del patrón: es lo que no es para sí, porque es lo que es en medio de una relación de fuerza, y la objetividad del coya ha sido constituida, histórica y estructuralmente, por el vencedor. $Y$ esta relación de fuerza es lo que Marx denominaba lucha de clases: el coya es el vencido y, vencido, es el vasallo del encomendero en la Colonia; después, con la República, la encomienda de indios se convierte, jurídicamente, en estancia o latifundio, y el encomendero en gamonal, y estructuralmente, el estado de dominación se conserva: el vasallo sigue siendo vasallo (Delfino et al. 2012a).

Estas comunidades padecieron la usurpación de sus tierras, pero también se vieron sometidas al despojo de su historia oral y de su patrimonio cultural material que de algún modo referenciaban las historias locales. Tal despojo, en buena medida fue operado por científicos que, en representación del proyecto moderno de estado cuando recorrían la región, proyectaron discursos de desvalorización y minimización de la complejidad de los procesos socioculturales locales y de sus características

\footnotetext{
5 El término coya, o colla, es habitualmente empleado en todo el noroeste argentino, aunque no siempre remite inequívocamente a un grupo étnico particular. Por extensión con el término coya se designan a los habitantes de la Puna, a las personas que habitan en lugares altos, por sobre los 2.000 m.s.n.m. También es empleado por quien vive abajo para referir al que vive arriba de él. El término coya es utilizado también como adjetivo, en este caso en alusión a lo que resulta nativo o autóctono (v.g. papa coya). Otro de los usos adjetivados del término implican aspectos negativos de la personalidad de un individuo (se lo suele usar como sinónimo de pícaro, atrasado, etc.).
} 
particulares. Desde los principios de la disciplina arqueológica en el Noroeste argentino, toda la región puneña se concibió como un lugar aislado, apenas un nexo por el que transitaban, migraban o comerciaban pueblos y caravanas entre un punto y otro, sin llegar a ser considerado como un lugar de vivienda sino temporaria, y haciéndola gravitar en la periferia de procesos sociales foráneos (Dupuy 2013b). De una forma o de otra, tradicionalmente los investigadores buscaron afiliar las evidencias arqueológicas encontradas a políticas expansionistas de sociedades más o menos distantes. Asimismo, desde los primeros relatos de viajeros y científicos a finales del siglo XIX, históricamente las descripciones producidas caracterizaron a los ámbitos campesinos, especialmente puneños, con connotaciones negativas y peyorativas ${ }^{6}$. Laguna Blanca fue descripta como una región poco acogedora, demasiado alejada de los centros poblados, de acceso difícil y con un clima tan duro que también daba sustento a cierta idea de pobreza natural y, por ende, cultural, de toda la región puneña.

Esta construcción literaria de la Puna produjo y permitió alimentar una interpretación sesgada del pasado prehispánico que se proyecta e impacta hasta las sociedades actuales. Dichos discursos formulados desde las esferas de poder de la sociedad capitalina argentina cumplían con intereses nacionalistas y centralizadores que, al construir una definición de las comunidades puneñas como periféricas en un proceso de subalternización, permitían legitimizar su avasallamiento: "(...) las expediciones de antaño en las cuales el intelectual "salvaba" los objetos de culturas menos civilizadas, las cuales no apreciaban el valor de estos, colocándolos en museos donde si lo harían" (Rivera Díaz 2004:25). Estos discursos del poder forman parte de un movimiento de colonización ideológica en la que los saberes-hacer, recursos y conocimientos tradicionales de los pobladores se encontraban desvalorizados e incluso desatendidos por ellos mismos.

Nos enfrentamos por lo tanto con una imagen politizada y polarizada construida mediante agentes exógenos, mandados usualmente por los mismos poderes provinciales y nacionales- a rendir cuenta de lo lejano que se encuentra la Puna, geográfica y culturalmente, respecto del marco referencial y discurso centralizador capitalino (Haber 1999). La historia local fue por otra parte considerada desde un punto de vista sumamente material, por su interés científico. Los objetos y relatos sustraídos durante las expediciones encargadas por el coleccionista porteño Benjamín Muñiz Barreto, por ejemplo, son

\footnotetext{
6 "Pobreza técnica y expresiva, falta de personalidad estilistica, área de paso de corrientes migratorias, estancamiento cultural, son las cualidades comunes con las cuales la arqueología de la Puna era cualificada"; "inferioridad cultural con relación a las áreas circunvecinas, dependencia comercial de los valles más ricos y, finalmente, el papel mediador entre los más importantes polos de desarrollo cultural a uno y otro lado de la Puna" (Haber 1999:31 y 37).
}

una expresión de ese afán por el acopio enfermizo, considerados exclusivamente como objetos de estudio despojados de los lazos simbólicos, históricos y sociales, seleccionados sobre criterios estéticos, y cuya función empieza con una expresión del poder para cierta élite que los ostenta y termina a lo sumo con dar a la comunidad científica -otra élite por cierto-, pretexto para su investigación, soporte a debates y peleas intestinas sobre cronologías y perfiles culturales. En ningún momento se planteó su rol fundamental en tanto elementos materiales y discursivos constitutivos de los procesos de construcción identitaria de las comunidades locales actuales. Al aislar los objetos, sitios, relatos y memoria colectiva en los tiempos lejanos de sociedades extintas, la ciencia funcionó como instrumento de invisibilización de las cargas semánticas y simbólicas que vehiculizaban hacia el presente, eliminando asimismo esta función de intermediarios en las relaciones con ancestros y abuelos ${ }^{7}$ que podían ocupar. El indio definitivamente tenía que ser una página cerrada de la historia argentina.

Sin embargo la diversidad sociocultural pasada de la región puede vislumbrarse en muchos aspectos, por ejemplo por la fuerte impronta material que dejaron los sucesivos procesos pasados en el territorio del Distrito de Laguna Blanca, a través de un extenso y diverso registro arqueológico que atestigua más de 2000 años de ocupación humana sedentaria y por lo menos 5000 años de presencia de grupos nómadas, con asentamientos y aldeas de hasta 450 hectáreas, gigantescas áreas acondicionadas para riego y cultivo con redes de canales, melgas y corrales de cultivo, y un abundante registro de sitios con un estilo local de arte rupestre. Por ello, pudimos definir que los grupos sociales que se asentaron en el pasado de Laguna Blanca generaron procesos estéticos con características propias (Barale y Delfino 2007), y una producción alfarera marcadamente local (Espiro 2007). Por otra parte, la supervivencia de prácticas antiguas vinculadas a la cosmogonía andina discurriendo paralelamente a las católicas que se sobre impusieron con intención de invisibilizarlas, siguen palpables en una multitud de aspectos cotidianos y de la vida ritual, encontrándose a lo largo de la macroregión puneña y surandina (como por ejemplo, los rituales de la Fiesta a la Pachamama o del Rupa Chico o Ruti Chico). Otro aspecto de la pervivencia de las antiguas culturas locales puede ser identificado en el uso de buena cantidad de términos que escaparon al colonialismo lingüístico español, fenómeno que suele ocurrir con los términos que abarcan ámbitos, o aspectos específicos que se mantienen por fuera de los intereses de los vencedores (términos relacionados con la cosmogonía justamente, la fauna y la flora, aspectos propiamente artesanales, etc., como por ejemplo, "checal", "chelco", y tantos otros).

\footnotetext{
7 Para los Lagunistos, los abuelos son parientes conocidos del pasado, a los cuales pueden acceder mediante recursos genealógicos de la memoria colectica. En cambio los "hermanos indios" son ancestros anónimos de un pasado más lejano.
} 


\section{Praxis museológica y articulación con los procesos identitarios}

Nos posicionamos políticamente, reivindicando la utilidad social de la producción de conocimiento científico y arqueológico (Delfino y Rodríguez, 1989; 1991), donde el Museo y sus discursos son escenarios de reivindicaciones y herramientas de resistencia y lucha. El Museo Integral de la Reserva de Biosfera de Laguna Blanca (Catamarca, Argentina) se creó en 1997, apoyándose en los fundamentos de la Mesa Redonda de Santiago de Chile de 1972 (ICOM 1972). Museo universitario', es también a la vez museo territorial, museo comunitario, museo crítico, escenario de luchas y tensiones, es un gran territorio de casi $10.000 \mathrm{~km}^{2}$ en la puna catamarqueña. En tanto expresión del "nuevo" museo, su misión abarca el (re)conocimiento del territorio vivido y construido por las comunidades locales, de los saberes subalternizados, abocándose a una co-producción de discursos que trae a escena la trama de valores y significados simbólicos vehiculizados por el patrimonio integral local, y restaurando el vínculo de estas narrativas entre el pasado y el presente en la sociedad local. En estas vivencias, el museo, en tanto institución universitaria politizada, asume una posición comprometida y de acompañamiento y apoyo permanente a las comunidades indígenas locales en la construcción de mecanismos de resistencia y restauración de sus legitimidades avasalladas. Desde esta perspectiva venimos acompañando el proceso local de posibles transformaciones sociales. Por lo tanto, una de las funciones ${ }^{9}$ del museo es la puesta a consideración de los conocimientos científicos para su resignificación / reapropiación por parte de las comunidades, defendiendo la praxis de una Arqueología Socialmente Útil (Delfino y Rodríguez 1991; Delfino 2001; Delfino, Manasse, Díaz y Pisani 2016). Por lo tanto, nuestros temas de investigación no van a ser adoptados desde la lógica interna que las comunidades científicas legitiman per se, sino que son definidos contextualmente desde una realidad que involucra a sujetos en una instancia co-productiva de conocimientos y acciones, (Delfino, Barale, Espiro y Díaz 2007). Así, nuestros planteos poseen puntos de coincidencia con las propuestas de la Investigación Acción Participativa (Martí 2000), persiguiendo un conocimiento colectivo, por proporcionar resultados cuya utilización y gobierno corresponden a los propios implicados, que deben haber determinado el proceso de conocimiento, a la vez que experimentado en el mismo un proceso de maduración colectiva. Una tarea que requeriría el establecimiento de un "contrato cognoscitivo" entre

\footnotetext{
8 Este museo depende de la Universidad Nacional de Catamarca (Argentina), y está bajo gestión del Instituto Interdisciplinario Puneño (InIP-UNCA).

9 "La utilidad social de los museos de arqueología es una "función" de la cantidad de vínculos que estos puedan establecer entre la actualidad y el pasado arqueológico. Cuando tales vínculos están ausentes, el público se siente ajeno al relato transmitido por medio de las colecciones" (Delfino 2001:8)
}

los participantes (Rabey y Kalinsky 1986). Este concepto no supone la sustitución de los propios modos de conocimiento por otros ajenos sino que pretende hacer "[...] confluir actitudes, percepciones, fragmentos de visiones del mundo", intereses y expectativas de un modo tal que las condiciones del vínculo delimitan el campo de las posibilidades de la verdad (Rabey y Kalinsky 1986). Sin embargo, esta sociedad en absoluto implica una relación armónica entendida como la ausencia de conflicto. Muy por el contrario, el desarrollo de nuestra experiencia conjunta posee tensiones, disrupciones e imposiciones asimétricas que fluctúan dependiendo de la situación. Los términos de los acuerdos se renegocian en cada decisión y los sentidos se re-significan desde los criterios de validación que cada socio cognoscitivo mantiene.

Enmarcamos así nuestra práctica en un ejercicio de continua interacción comunitaria, en torno a temáticas tan diversas como lo es el museo mismo: las prácticas agrícolas, saberes-hacer textil y alfarero, constructivo, conocimiento de las rutas tradicionales de intercambio, etc. Trabajamos en distintas acciones de apoyo a la consolidación del acelerado proceso de re-etnización/ etnogénesis que se está activando en los últimos años en las poblaciones de la región, buscando promover la (re)expresión de la dimensión comunitaria y social que sostuvo históricamente y sigue sosteniendo el modo de vida campesino y puneño. Este proceso de reivindicación identitaria, girando centradamente en la recuperación de tierras comunitarias, está dialogando con la reapropiación y revalorización del pasado indígena por parte de las comunidades. Por ello hemos centrado nuestros esfuerzos en la restauración de los "saberes sometidos" (Foucault 2008), descubriendo y re-construyendo la historia local a través de la investigación arqueológica de los vestigios o antigales, de la investigación etnográfica de la memoria, la oralidad y las tradiciones, y de espacios de interacción con los pobladores (entrevistas, talleres, ceremonias y festividades). La materialización de instancias de coproducción de narrativas del pasado entre universitarios (docentes y estudiantes) y las comunidades de la región, desarrolladas por los sucesivos proyectos llevados adelante por el equipo del Instituto Interdisciplinario Puneño, está permitiendo erigir nuevos espacios de expresión de otras voces de la historia local. La enseñanza de la Historia en las instituciones escolares de la región ha producido una homogeneización de los sentidos históricos, instituyendo un discurso hegemónico en el que se sometían a las discursividades locales, negando su agencialidad histórica (Foucault 2008). La negación del saber local en la institución escolar, en tanto aparato ideológico del Estado (sensu Althusser 1974), se produce no sólo a nivel del saber campesino, sino también a nivel académico, es decir, excluyendo de la enseñanza de la Historia los procesos históricos que han tenido lugar en las localidades. Los procesos de re-etnización exigen otros significados que los que las instituciones escolares imparten, pues lo que hasta este momento se sostenía 
en las prácticas domésticas y comunitarias como un saber sometido, avasallado, reivindica su presencia en una Sociedad multicultural: se trata, pues, de introducir los sentidos ausentes en las aulas, de re-significar la Historia que se enseña introduciendo la discursividad campesina, los sentidos-Otros, y la crítica histórica y política de las investigaciones antropológicas.

El patrimonio cultural juega por lo tanto ese importante rol al permitir la apropiación y el (re)conocimiento de discursos y saberes-hacer pasados, así como constituir una base de intercambio y diálogo entre las diferentes comunidades o círculos sociales en presencia (Declaration of Paris 2011; UNESCO/ICOMOS 2011).

En este marco queremos subrayar los esfuerzos comunitarios hacia una restauración de estos "saberes sometidos", en la cual la integración de la investigación arqueológica de los vestigios históricos, la investigación etnográfica de la memoria, la oralidad y las tradiciones, la museografía y los espacios de interacción con los pobladores permiten re-descubrir y re-construir la historia local.

En un primer tiempo, hemos abogado por la escenificación de significados sociales locales, producidos sobre la base de las investigaciones arqueológicas y etnoarqueológicas que llevamos adelante en la región desde hace más de un cuarto de siglo. Es así como la muestra permanente del Centro de Interpretación del Museo pone en evidencia distintos aspectos de la diversidad y riqueza locales, en contraposición con los prejuicios mencionados anteriormente, históricamente construidos sobre la región. La muestra está destinada a oponer estos discursos a la evidencia arqueológica atestiguando la riqueza productiva local (agrícola, alfarera, textil, pastoril), los intercambios activos manifiestos con zonas más o menos alejadas (como la costa chileno-peruana y las yungas), las prácticas claramente producto de ellos (moluscos marítimos, obsidianas, consumo de rapé, etc.) y a su vez la proyección de las culturas locales a nivel regional y macroregional.

En nuestro recorrido hacia la re-construcción de un relato colectivo local, vimos en la historia oral e historias de vida, una herramienta metodológica para generar narrativas de la vida y experiencias cotidianas de la comunidad en relación a la Aldea Laguna Blanca. La historia oral nos devuelve las narrativas que han sido marginadas o desplazadas de la historia anterior y oficial, tornando a la historia menos parcial y de manera directa nos remite a la memoria, restituyendo el pasado a partir del presente. La memoria es siempre colectiva, al estar determinada por el contexto presente de la persona o de los colectivos que están reconstruyendo el pasado. Es por tanto un elemento constituido de la identidad, un elemento para el reconocimiento y valoración tanto individual como grupal. La historia oral permite ver cómo la memoria de los pueblos se constituye y transmite, presentándose como una alternativa metodológica al momento de legitimar un determinado bien para asignarle un valor patrimonial para una determinado grupo social. Pero incluso, cuando el registro arqueológico resulta esquivo, la memoria, la oralidad, hasta las nominaciones de marcas territoriales en muchas ocasiones han servido no solo para replantear investigaciones y generar nuevas preguntas, sino para traer a interpelación historias silenciadas, como lo es por ejemplo el problema de la negritud en Laguna Blanca.

Entrelazando la necesidad de aportar otro discurso histórico que superara los sesgos de intereses centralistas, con la riqueza de la historia oral, logramos co-producir un cuadernillo destinado a circular dentro de las comunidades, y especialmente en la educativa local, donde sirvió de base para una reflexión sobre la construcción identitaria local. Su apropiación pasó por su uso como material de apoyo en clase, hasta su adaptación en radio-teatro, cuya obra itinerante y actores (los alumnos de la Escuela Primaria $N^{\circ}$ 450 "Maestro Scidá"), recorrieron parte de la Provincia.

En los últimos diez años, las familias campesinas de la región comenzaron a reconocerse y organizarse como comunidades indígenas, con el objeto de reivindicar sus derechos históricos sobre la tierra y acabar con los abusos que venían sufriendo por parte de las familias terratenientes, conformándose a la fecha cinco comunidades: Comunidad Indígena de Corral Blanco, Comunidad Indígena La Angostura, Comunidad Indígena de Aguas Calientes, Comunidad Indígena de Laguna Blanca y Comunidad Indígena de Carachi. Las comunidades no están hechas sino que se tienen que hacer constantemente. Es decir, toda comunidad es una organización práctica $y$, en tanto tal, no es sino en la medida en que se hace, en la superación práctica de las familias hacia una unidad de orden superior, contra las fuerzas de la serialidad que la corroen y que amenazan siempre con devolverla al estado de dispersión, y que se busca contrarrestar a través de las ceremonias (como en Laguna Blanca, por ejemplo, la ceremonia de la Corpachada a la Pachamama ${ }^{10}$ que, desde hace unos diez años, tiene lugar cada $1^{\circ}$ de agosto) y de prácticas comunitarias como el chaku o encierro de vicuñas, que en este caso supone superar prácticas de furtivismo en nombre de la gestión comunitaria de un recurso que es entendido ahora como un bien común (Pisani 2017).

\footnotetext{
10 Del quechua, literalmente: madre tierra, la principal deidad andina. En esta fecha, se celebra a la Madre Tierra en su momento más débil, en el punto más frio del invierno, donde por medio de ofrendas podemos a la vez agradecerla por los recursos (hacienda, cosechas, etc.) que nos ha proveído desde el invierno anterior, y pedirle su ayuda con producciones suficientes en el año productivo que va a empezar con la primavera inminente. Para el ritual de la corpachada se cava un pozo que servirá para depositar las ofrendas a la Pachamama. Desde este pozo se "da de comer a la tierra" (se "corpacha": palabra derivada del término quechua "korpa" que significa huésped o invitado o tal vez más bien de "korpachaj", es decir huésped, el que da hospitalidad), siendo las principales ofrendas las hojas de coca, el tabaco y el alcohol.
} 
Además de implicar un proceso de organización comunitaria y de afirmación de elementos culturales prehispánicos, este proceso de reetnización constituye una estrategia para redefinir las relaciones de poder, y abordar así el problema de la tierra (Pisani 2017). El papel del Museo, en tanto herramienta de resistencia, se manifestó, en este esfuerzo de acompañamiento de la organización comunitaria y afirmación étnica, en su participación en los relevamientos territoriales en pos del reconocimiento de sus estatus jurídicos de "pueblos originarios" otorgados por el Estado nacional. En 2015, los comuneros de la Comunidad Indígena La Angostura y su cacique, Bernardo G., solicitaron nuestro apoyo científico en las tareas destinadas a llevar adelante los registros para dar cumplimiento a los requerimientos de la Ley 26.160 sobre Emergencia Territorial Indígena. Es así como se realizaron una cartografía participativa y el relevamiento territorial completo en conjunto. En el transcurso de dichas tareas, los comuneros nos compartieron su deseo de materializar un museo comunitario sobre su territorio, escenario de un discurso propio en torno a los vínculos inextricables que se siguen tejiendo entre patrimonio integral y territorio, y su inserción en la trama de sociedades y comunidades regionales, tanto históricas como antiguas. Hemos iniciado estas mismas tareas de cartografía en conjunto con la comunidad de Corral Blanco y su cacique Rosa S., y con la comunidad de Laguna Blanca y su cacique Enzo G. Estos proyectos a su vez están fortaleciendo al Museo Integral, retroalimentándolo y afianzando su rol como vehículo de acción y comunicación dentro de la comunidad, coproduciendo prácticas y conocimientos que podrán a su vez ser compartidos con los pobladores y visitantes.

Siendo partícipe y actor de estos procesos de reivindicación de las familias campesinas en tanto sujetos indígenas para afirmar su derecho histórico a una tierra que le ha sido enajenada, el equipo universitario del Museo pasó a ser inquirido en un rol de apoyatura científico-técnica en temas atinentes a identidad y afirmación de derechos indígenas, por lo que ha estado invitado formalmente a participar de algunas asambleas de comuneros convocadas por las Uniones de Pueblos Diaguitas de Catamarca y de Tucumán, y es consultado para asesorar y acompañar a los relevamientos territoriales de otras comunidades. En este sentido, también se ha participado en la realización de módulos de formación con líderes de la Escuela de Gobernanza Indígena de Amaicha del Valle (Provincia de Tucumán).

Fruto del trabajo en conjunto con la comunidad, la creación de un sendero de interpretación sobre las tierras de la Comunidad Indígena de Laguna Blanca descansa, en gran parte, sobre el recurso a la historia local para generar un discurso de la comunidad sobre ella misma, siendo ella dueña y anfitriona del territorio y de su relato. Los comuneros están actualmente llevando adelante la acogida de visitantes y las visitas en su territorio por medio de este sendero. Así, la puesta en valor patrimonial del sitio arqueológico de memoria "L'Abrita" como Museo de Sitio, apunta a dinamizar el uso del recurso arqueológico y patrimonial integral como fuente de legitimación y soporte de discursos de reivindicación por esta comunidad, en cuyas tierras se encuentran tanto el sitio como el sendero de interpretación que permite llegar a él. Los comuneros manifestaron el deseo de crear una pequeña plaza al inicio del sendero, donde también construirían un puesto de pastores, tal como el que está a la mitad del recorrido del sendero, donde prevén preparar tortillas, maté cocido y sal chancada para proponer algunos sabores locales a los visitantes a la vez que desean ofrecerles los productos de su trabajo.

Otro de los ejemplos en los que ha quedado articulado nuestro trabajo tuvo por escenario la reapropiación del patrimonio construido y de las tradiciones constructivas locales. Podemos citar como ejemplo la actualización y reformulación de un plano constructivo tradicionalmente expresado en los antiguos puestos de pastores, y que aparece en sitios arqueológicos de más de 2000 años de la región. Cuando Delfino empezó a trabajar en la región de Laguna Blanca a principios de los '90 ya se notaba un fuerte impacto de los modos de vida urbanos. Poco a poco los pobladores habían empezado a desconsiderar sus propias tradiciones constructivas para seguir las tendencias urbanas, moda del "progreso": materiales y plan arquitectónico "importados" de los centros urbanos (Delfino 2001). La Ley 24.856 sancionada en 1997, conocida como "Ley de Erradicación de EscuelasRanchos", formulada desde las oficinas de gobierno de una lejana capital nacional (1500 km) y aplicándose específicamente a las escuelas públicas, traía técnicas constructivas propias de una ideología de dominación impuesta en la región y vino acelerando la corriente de abandono de las viviendas tradicionales (Delfino 2015). Apuntando a hacer desaparecer los rastros de arquitecturas tradicionales pero según los decisores, "precarias", poco saludables y finalmente, reveladoras de pobreza, y plasmada específicamente en las escuelas, era la expresión del "aparato ideológico del Estado" cuya finalidad práctica se inscribe en la dominación hegemónica de las poblaciones marginadas o subalternas. No se puede dejar de observar la función ideológica de las instituciones escolares en las sociedades capitalistas, en tanto constituyen un aparato de encauzamiento de la conducta y vigilancia de la población. La estandarización de su arquitectura, la integración de sus edificios en las comunidades, la asistencia obligatoria, son tantos aspectos que sirven a la intromisión del discurso político en las comunidades, aunque en forma menos marcada -o más sutil-, que los contenidos mismos, también objetables por su parcialidad (cf. Delfino 2015; Delfino et al. 2013). En este contexto, se decidió partir del diseño de planta circular de los puestos tradicionales de pastores y de los espacios de las viviendas arqueológicas de la región y adaptarlo en octógonos para la construcción del Centro 
de Recepción e Interpretación (CRI) y la Residencia Universitaria del Museo Integral, usando además los materiales locales tradicionales (bases de piedras, paños de adobe y techos de cañizo y barro pisado).

Años más tarde, en 2013, se inauguró la Casa de la Puna en San Fernando del Valle de Catamarca, retomando el formato de octógonos del CRI del Museo Integral. En ambos casos la arquitectura tradicional fue puesta en evidencia en un edificio institucional, funcionando como vitrina de los saberes-hacer de una franja de población invisibilizada. En el lapso que transcurrió entre ambas inauguraciones, el primer edificio empezó a cumplir su papel de estandarte arquitectónico de la identidad puneña. Es así como hemos visto reproducirse y esparcirse los módulos octogonales: el Centro de Recepción e Información Turística, de Laguna Blanca, el Museo Comunitario de Barranca Larga, el Centro de Recepción e Información Turística de Villa Vil y el Mercado Artesanal Municipal "Huilla Huil", el albergue estudiantil de la Escuela Primaria n¹63 de Aguas Calientes y, especialmente la construcción de casas particulares de pobladores de Laguna Blanca.

Como hemos visto, desde nuestra práctica, buscamos generar las condiciones y el espacio en una interacción de los campesinos e indígenas como sujetos históricos, para permitir un proceso de restauración de los saberes sometidos, saberes de una praxis que cuestiona las prácticas estatales y prácticas académicas. Consideramos fundamental el generar las instancias que den posibilidad para un trabajo de reparación histórica, el volver a traer los sujetos, memorias, cuerpos, relatos invisibilizados y subalternizados. Hemos posicionado en esta lucha el rol de nuestro museo y la función central de nuestra praxis científica. En este camino existen numerosas tensiones, en una ida y venida entre los colectivos presentes (y, también, pasados), que nos permiten un pretexto para afirmar permanentemente nuestra posición ética, y necesariamente politizada, frente a una construcción histórica nacional arrolladora. Se trata de un ejercicio de continua reformulación y reacomodamiento, del que necesariamente las comunidades nos devuelven una resignificación. Es, sencillamente, un proceso vivo, con colectivos vivos, desde un museo vivo.

San Fernando del Valle de Catamarca, 31 de Agosto 2018

\section{Referencias citadas}

Althusser, L. 1974 [1970]. Ideología y aparatos ideológicos del Estado. Buenos Aires: Ediciones Nueva Visión.

Barale, A., D. Delfino. 2007. De los dibujos de la cerámica de una aldea arqueológica a los textiles artesanales: el desarrollo local y la arqueología en Laguna Blanca.
Aportes Científicos desde Humanidades, 7, 225-235.

Bender, D. R. 1967. A Refinement of the Concept of Household: Families, Co-residence, and Domestic Functions. American Anthropologist 69: 493-504.

Delfino, D. 2001. La planificación del Museo Integral en Laguna Blanca: un proyecto testigo en la Puna catamarqueña (Argentina). Debates sobre la gestión del patrimonio cultural. Tesis de Maestría de Arqueología Social de Iberoamérica. Huelva, España. Inédita.

Delfino, D. 2015. Los vendavales de políticas estatales y el resistente lenguaje de las 'casas mochas' en la puna catamarqueña". Cuadernos, 47, 181-195. San Salvador de Jujuy.

Delfino, D., P. G. Rodríguez. 1989. Cuando los arqueólogos vienen marchando: Interrogantes y propuestas en torno a la defensa y el rescate del patrimonio arqueológico. Revista de Antropología. Una búsqueda del hombre del Tercer Mundo. Año IV (7), 51-57. Buenos Aires.

Delfino, D., P. G. Rodríguez. 1991. Crítica de la arqueología 'pura': De la defensa del patrimonio hacia una arqueología socialmente útil. Guayaquil: Centro de Estudios Arqueológicos y Antropológicos (CEEA).

Delfino, D., V. E. Espiro y R. A. Díaz. 2007. ¿Tierras vacas o complicidad administrativa? La reorientación económica del Bolsón puneño de Laguna Blanca a partir de la colonia. Memorias del III Congreso de Historia de Catamarca, Tomo I: 107-124. Catamarca: Editorial Científica Universitaria.

Delfino, D., A. Barale, V. E. Espiro y R. A. Díaz. 2007. Veinte años de arqueología socialmente útil. Problemas y resultados de una práctica con la comunidad de Laguna Blanca. IV Reunión Internacional de Teoría Arqueológica en América del Sur - Inter WAC. Ponencia presentada en San Fernando del Valle de Catamarca. Inédita.

Delfino, D., A. Barale, R. A. Díaz, S. Dupuy, V. E. Espiro, M. G. Pisani, M. C. Cuello Bulacios, M. Gamboa, y C. A. González. 2012a. Pasado local, procesos de re-etnización y arqueología: experiencias desde el Museo Integral de la Reserva de Biosfera de Laguna Blanca. III Encuentro de Museos Universitarios del Mercosur. Museos: memoria + creatividad = cambio social. Santa Fe, Argentina. Ponencia inédita.

Delfino, D., A. Barale, R. A. Díaz, S. Dupuy, V. E. Espiro, M. G. Pisani, M. C. Cuello Bulacios, M. Gamboa y C. A. González. 2012b. Confluencias entre el Museo Integral de la Reserva de Biosfera de Laguna Blanca y una arqueología socialmente útil en la Puna catamarqueña. III Encuentro de Museos Universitarios del Mercosur. Museos: memoria + creatividad $=$ cambio social. Santa Fe, Argentina . 
Ponencia inédita.

Delfino, D., A. Barale, R. A. Díaz, S. Dupuy, V. E. Espiro y M. G. Pisani. 2013. El Museo Integral de la Reserva de Biosfera de Laguna Blanca como soporte y vehículo de confrontaciones discursivas, de prácticas académicas y campesinas. Actas del IV Encuentro de Museos Universitarios del Mercosur. I Encuentro de Museos Universitarios Latinoamericanos y del Caribe: 150-161. Santa Fe: Universidad Nacional del Litoral.

Delfino, D., M. G. Pisani. 2014. La casa, los pastos y el cobrador. Del extrañamiento histórico de la tierra y de las relaciones de dominación y vasallaje en Laguna Blanca, Catamarca. Primeras Jornadas Regionales y Terceras Jornadas Internas de Antropología. Salta, Argentina. Inédita.

Delfino, D., B. Manasse, R. A. Díaz y M. G. Pisani. 2016. La arqueología socialmente útil y la arqueología pública. Reflexiones desde la praxis. Actas del XIX Congreso Nacional de Arqueología Argentina, Serie monográfica y didáctica 54: 2648-2653. San Miguel de Tucumán.

Dupuy, S. 2013a. Desde una búsqueda museológica, hacia la reapropiación patrimonial de las comunidades puneñas de Laguna Blanca (Catamarca-Argentina). IV Encuentro de Museos Universitarios del Mercosur. I Encuentro de Museos Universitarios Latinoamericanos y del Caribe: 162-175. Universidad Nacional del Litoral, Santa Fe.

Dupuy, S. 2013b. Plan de musealización de la Aldea Arqueológica Laguna Blanca y la instalación Inca Caranchi Tambo (Museo Integral de la Reserva de Biosfera de Laguna Blanca, Catamarca, Argentina). Memoria de Máster. Universidad de Alcala, España. Inédita.

Espiro, V. 2007. Aportes para una clasificación tecnológica de las cerámicas pertenecientes al primer milenio de nuestra era de la Aldea Piedra Negra, Laguna Blanca, Dpto. Belén, Provincia de Catamarca. Tesis de licenciatura, Universidad Nacional de Catamarca. Inédita.
Foucault, M. 2008 [1997]. Defender la sociedad. Buenos Aires: Fondo de Cultura Económica.

Haber, A. F. 1999. Una arqueología de los oasis puneños Domesticidad, interacción e identidad en Antofalla, primer y segundo milenios $d$. C. Tesis de Doctorado. Universidad de Buenos Aires, Argentina.

Horkheimer, H. 1990. Alimentación y Obtención de Alimentos en los Andes Prehispánicos. La Paz: Editorial Hisbol.

ICOM. 1972. Mesa redonda sobre la importancia y el desarrollo de los museos en el mundo contemporáneo. Santiago de Chile.

Martí, J. 2000. La investigación-acción participativa. Estructura y fases. Construyendo ciudadanía, vol. 1, La investigación social participativa. Villasante, T.R.; Montañés, M; Martí, J. (coord.). Barcelona: El Viejo Topo.

Naciones Unidas, Declaración de las Naciones Unidas sobre Derechos de los Pueblos Indígenas, 13 de septiembre de 2007.

Pisani, M. G. 2018. Reflexiones teórico-metodológicas sobre el valor heurístico del concepto de «campesinado indígena» en los Andes a partir del estudio de caso de Laguna Blanca, Catamarca. Estudios de Historia y Antropología. En prensa.

Rabey, M., B. Kalinsky. 1991. El contrato cognoscitivo. Los antropólogos también son seres humanos. Cuadernos de Epistemologia de las Ciencias Sociales 1: 19-42. Buenos Aires.

Rivera Díaz, J. A. 2004. Robo y tráfico ilícito de bienes culturales. Memoria presentada a la Facultad de Artes de la Universidad de Chile para optar a la Licenciatura de Teoría e Historia del Arte. Santiago de Chile.

UNESCO / ICOMOS. 2011. Déclaration de Paris. Sur le patrimoine comme moteur du développement. XVIle Assemblée Générale. Paris, 1 ero de diciembre de 2011. 